\title{
A novel genus and cryptic species harboured within the monotypic freshwater crayfish genus Tenuibranchiurus Riek, 1951 (Decapoda: Parastacidae)
}

\author{
Kathryn L Dawkins ${ }^{\text {Corresp., }}{ }^{1}$, James M Furse ${ }^{2,3}$, Clyde H Wild ${ }^{2}$, Jane M Hughes ${ }^{4}$ \\ ${ }^{1}$ Australian Rivers Institute, Griffith University, Gold Coast, Queensland, Australia \\ 2 Environmental Futures Research Institute, Griffith University, Gold Coast, Queensland, Australia \\ 3 Miyazaki International College, Miyazaki, Japan \\ 4 Australian Rivers Institute, Griffith University, Nathan, Queensland, Australia \\ Corresponding Author: Kathryn L Dawkins \\ Email address: kathryn.dawkins1@gmail.com
}

Identifying species groups is an important yet difficult task, with there being no single accepted definition as to what constitutes a species, nor a set of criteria by which they should be delineated. Employing the General Lineage Concept somewhat circumvents these issues, as this concept allows multiple concordant lines of evidence to be used as support for species delimitation, where a species is defined as any independently evolving lineage. Genetically diverse groups have previously been identified within the monotypic parastacid genus Tenuibranchiurus Riek, 1951, but no further investigation of this diversity has previously been undertaken. Analysis of two mitochondrial DNA gene regions has previously identified two highly divergent groups within this taxon, representing populations from Queensland (QId) and New South Wales (NSW), respectively. Additional testing within this study of both mitochondrial and nuclear DNA through species discovery analyses identified genetically diverse groups within these regions, which were further supported by lineage validation methods. The degree of genetic differentiation between QId and NSW populations supports the recognition of two genera; with Qld retaining the original genus name Tenuibranchiurus, and NSW designated as Gen. nov. until a formal description is completed. Concordance between the species discovery and lineage validation methods supports the presence of six species within Tenuibranchiurus and two within Gen. nov.. The recognition of additional species removes the monotypy of the genus, and the methods used can improve species identification within groups of organisms with taxonomic problems and cryptic diversity. 
1 A novel genus and cryptic species harboured within the monotypic freshwater

2 crayfish genus Tenuibranchiurus Riek, 1951 (Decapoda: Parastacidae)

3

4 Kathryn L. Dawkins ${ }^{1}$, James M. Furse ${ }^{2,3}$, Clyde H. Wild ${ }^{2}$, Jane M. Hughes ${ }^{4}$

$5 \quad{ }^{1}$ Australian Rivers Institute, Griffith University, Gold Coast, Qld 4222, Australia

6 'Environmental Futures Research Institute, Griffith University, Gold Coast, Qld 4222, Australia

7 3Miyazaki International College, Miyazaki, Japan

$8 \quad{ }^{4}$ Australian Rivers Institute, Griffith University, Nathan, Qld 4111, Australia

Corresponding Author:

Kathryn Dawkins ${ }^{1}$

kathryn.dawkins1@gmail.com

\section{Abstract}

Identifying species groups is an important yet difficult task, with there being no single accepted definition as to what constitutes a species, nor a set of criteria by which they should be delineated. Employing the General Lineage Concept somewhat circumvents these issues, as this concept allows multiple concordant lines of evidence to be used as support for species delimitation, where a species is defined as any independently evolving lineage. Genetically diverse groups have previously been identified within the monotypic parastacid genus Tenuibranchiurus Riek, 1951, but no further investigation of this diversity has previously been undertaken. Analysis of two mitochondrial DNA gene regions has previously identified two highly divergent groups within this taxon, representing populations from Queensland (Qld) and New South Wales (NSW), respectively. Additional testing within this study of both mitochondrial and nuclear DNA through species discovery analyses identified genetically diverse groups within these regions, which were further supported by lineage validation methods. The degree of genetic differentiation between Qld and NSW populations supports the recognition of two genera; with Qld retaining the original genus name Tenuibranchiurus, and NSW designated as Gen. nov. until a formal description is completed. Concordance between the species discovery and lineage validation methods supports the presence of six species within Tenuibranchiurus and two within Gen. nov. The recognition of additional species removes the 
32 monotypy of the genus, and the methods used can improve species identification within groups of organisms with taxonomic problems and cryptic diversity.

\section{INTRODUCTION}

Species are the fundamental unit of biodiversity; yet there has always been disagreement about criteria by which they should be recognised and the methods by which they should be delineated, with no general consensus reached thus far. The lack of one clearly accepted definition of a "species" creates obvious limitations, as what one person regards as a species may not be regarded as being so by another person, which is often further exacerbated by differences of opinion between fields of study. Employing the General Lineage Concept (GLC; de Queiroz 1998), where a species is defined as a metapopulation lineage evolving separately from other lineages, somewhat unites the various species concepts by allowing any evidence of lineage separation (and thus any property emphasised by the alternative concepts) to be used as evidence for species delimitation (de Queiroz 2007). Not only does this concept allow multiple lines of evidence to be used, but it also allows the evolutionary processes that have caused divergence between lineages to be examined.

Identifying species within freshwater crayfish has traditionally been undertaken through morphological examination. However, due to the tendency of crustaceans to contain both morphologically plastic or cryptic forms (e.g. Austin \& Knott 1996; Breinholt et al. 2012; Murphy \& Austin 2003; Silva et al. 2010), there has been an increasing shift towards the use of molecular methods to identify cryptic diversity (Bentley et al. 2010; Dawkins et al. 2010; Hansen et al. 2001; Mathews et al. 2008; Schultz et al. 2007; Sinclair et al. 2011). With the use of molecular techniques comes the potential for signatures of population-level and species-level histories to become confounded, however (Edwards 2008). This can occur when gene trees constructed from a single locus differ from the true genealogical history of a species (Hey \& Machado 2003; Sunnucks 2000), although this problem can potentially be overcome by estimating gene trees from multiple unlinked loci. Using multiple loci from different areas of the genome (e.g. mtDNA and nuDNA) can account for the different patterns of evolution experienced by each. For instance, mitochondrial alleles accumulate nucleotide substitutions several times faster than nuclear genes due to their lower effective population size, thereby 
63 completing the coalescent process much faster and becoming diagnostic of taxa more rapidly

64 (Sunnucks 2000).

65

66

67

68

Once a species tree has been inferred, additional testing is often undertaken to provide support for the proposed species' groups. A range of statistical analyses are available for testing species boundaries and, as there is currently no universally accepted way to define species, there are also a range of critiques on these methods (e.g. Blaxter 2004; Brower 1999; Ebach \& Holdrege 2005; Lipscomb et al. 2003; Seberg et al. 2003; Sites \& Marshall 2003; Sneath \& Sokal 1973; Tautz et al. 2002; Tautz et al. 2003; Wiens \& Penkrot 2002; Wiens \& Servedio 2000; Will et al. 2005; Yang \& Rannala 2010). Under the GLC, any evidence of lineage separation can be evidence for the existence of different species (de Queiroz 2007); as such, the identification of numerous corroborating lines of evidence (through the use of multiple tests) can be seen as lending support to any species boundaries that are defined. Therefore, although no single test is currently universally accepted, the apparent need to choose a particular method is circumvented by using a selection of techniques and multiple gene regions as, under the GLC, concordance between multiple lines of evidence is seen as increasing the rigour of species delimitation.

The parastacid crayfish genera are generally highly speciose, with novel species and genetically diverse groups commonly found (e.g. Coughran 2005; Coughran et al. 2012; Furse et al. 2013; Hansen \& Richardson 2006). The most notable exception to this is the genus Tenuibranchiurus, which contains the species with the smallest body size in the Parastacidae Huxley, 1879. Although it has previously been highlighted as containing genetically diverse groups (see Dawkins et al. 2010; Horwitz 1995), this genus as currently recognised contains only the single described species Tenuibranchiurus glypticus Riek, 1951. Tenuibranchiurus falls within a monophyletic clade containing the other Australian burrowing crayfish (Gramastacus Riek, 1972, Geocharax Clark, 1936, Engaewa Riek, 1967, Engaeus sensu stricto Erichson, 1846, and Engaeus lyelli (Clark, 1936) (distinct from other Engaeus species, sensu Schultz et al. 2009)) (Horwitz 1988), and is endemic to the central-eastern coast of Australia, spanning south-east Queensland (Qld) and north-eastern New South Wales (NSW) (Fig. 1). It was first suggested by Horwitz (1995), on the basis of electrophoretic and geographical differences, that previously unrecognised genetic diversity existed within the genus. Subsequently, two genetically divergent 
94 groups were identified within this region by Dawkins et al. (2010), both of which showed

95

96

97

98

99

100

101

102

103

104

105

106

107

108

109

110

111

112

113

114

115 considerable internal genetic variability. The two identified groups aligned with populations from Qld and NSW, respectively, and were suggested to represent species that diverged as a result of long-term historical geographic isolation (Dawkins et al. 2010). The present study seeks to quantify the genetic diversity present within Tenuibranchiurus, utilising molecular data across several gene regions and employing multiple species delimitation methods in order to determine the most likely species groups.

\section{METHODS}

A total of 133 specimens were collected across 16 field localities, including the type locality for T. glypticus. All specimens from this study were collected under permits WITK08599510, WISP08599610, and TWB/01/2011 issued by the Department of Environment and Resource Management. DNA was extracted from specimens preserved in $70 \%$ ethanol using a variation of the cetyltrimethyl ammonium bromide/phenol-chloroform extraction protocol (Doyle \& Doyle 1987). Two mitochondrial gene regions (cytochrome oxidase subunit 1 (COI) and 16S rDNA $(16 \mathrm{~S})$ ) and three nuclear gene regions (glyceraldehyde-3-phosphate dehydrogenase (GAPDH), histone-3 (H3), and arginine kinase (AK)) were amplified (see Table 1 for primer list).

Sequences were edited using Sequencher 4.9 (GeneCodes 2009) and aligned using the MUSCLE addition in MEGA5 (Edgar 2004). Alignments were then checked and edited by hand if necessary.

Table 1. Forward and reverse primers used for PCR amplification and DNA sequencing.

\begin{tabular}{|c|c|c|c|}
\hline Gene region & Primers $\left(5^{\prime} \rightarrow 3^{\prime}\right)$ & Reference & Fragment length \\
\hline $\mathrm{COI}$ & $\begin{array}{l}\text { CRCOI-F: CWACMAAYCATAAAGAYATTGG } \\
\text { CRCOI-R: GCRGANGTRAARTARGCTCG }\end{array}$ & Cook et al. (2008) & $644 \mathrm{bp}$ \\
\hline $16 \mathrm{~S}$ & $\begin{array}{l}\text { 16S-ar: CGCCTGTTTATCAAAAACAT } \\
\text { 16S-br: CCGGTCTGAACTCAGATCACGT }\end{array}$ & Palumbi et al. (1991) & $449 \mathrm{bp}$ \\
\hline GAPDH & $\begin{array}{c}\text { G3PCq157-F: TGACCCCTTCATTGCTCTTGACTA } \\
\text { G3PCq981-R: ATTACACGGGTAGAATAGCCAAACTC }\end{array}$ & Buhay et al. (2007) & $563 \mathrm{bp}$ \\
\hline H3 & $\begin{array}{l}\text { H3-AF: ATGGCTCGTACCAAGCAGACVGC } \\
\text { H3-AR: ATATCCTTRGGCATRATRGTGAC }\end{array}$ & Colgan et al. (1998) & $264 \mathrm{bp}$ \\
\hline $\mathrm{AK}$ & $\begin{array}{l}\text { AKcray-F: CTACCCCTTCAACCCCTGCCTT } \\
\text { AKcray-R: CGCCCTCTGCTTCGGTGTGCTC }\end{array}$ & $\begin{array}{l}\text { J.W. Breinholt } \\
\text { unpublished data }\end{array}$ & $538 \mathrm{bp}$ \\
\hline
\end{tabular}




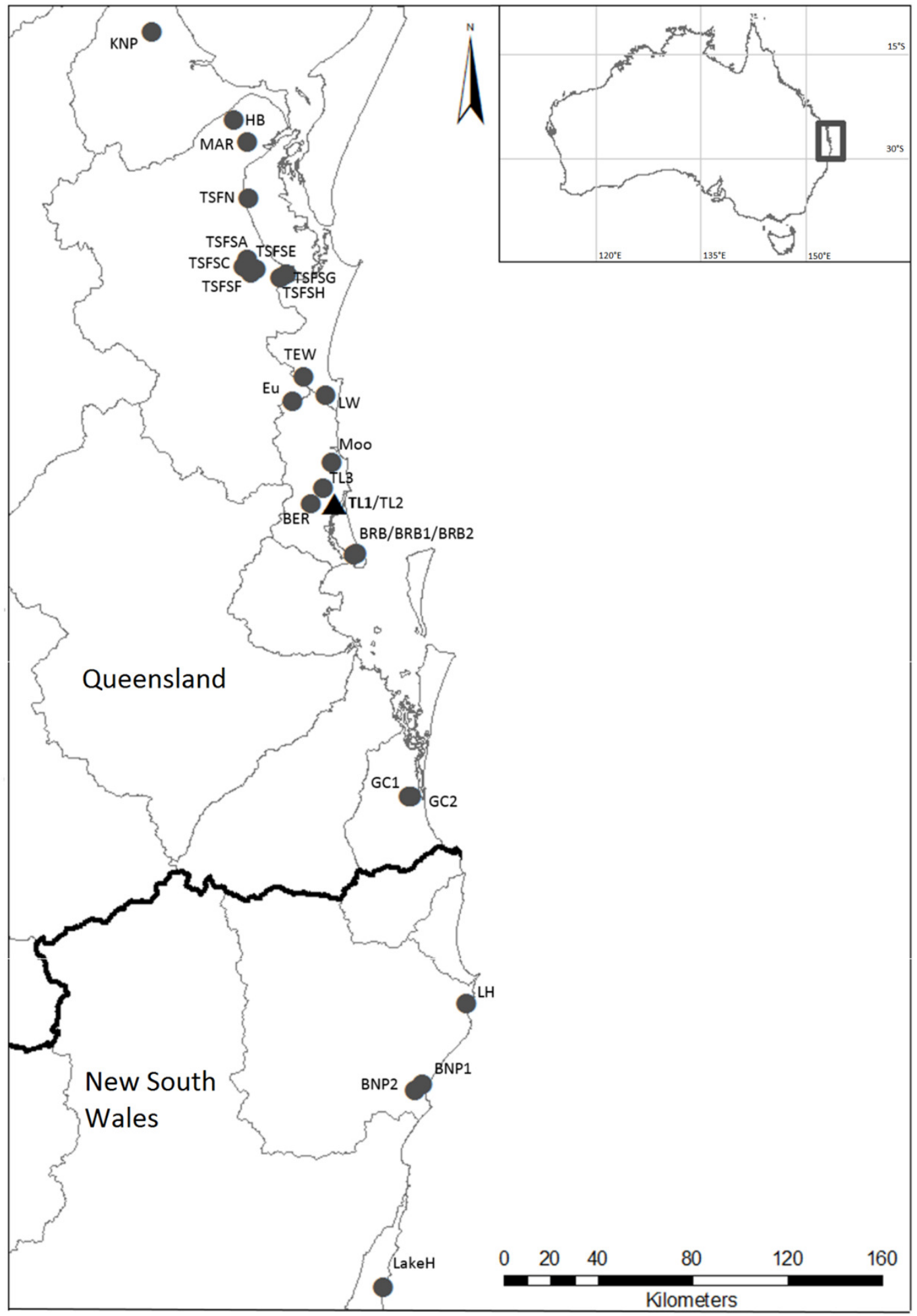

Figure 1. Localities where specimens of Tenuibranchiurus were collected during this study. The triangle and bolded name denotes the Type Locality. Grey lines denote drainage boundaries, and the black line denotes the border between Queensland and New South Wales. Refer to Table 2 for collection details. 


\section{Phylogenetic Analyses}

118 A total of 127 Tenuibranchiurus samples were sequenced for the COI gene fragment, 59 for 16S,

11993 for GAPDH, 57 for H3, and 46 for AK (Table 2). Additional specimens from the genera

120 Gramastacus, Geocharax, Engaeus, Engaewa, and Cherax were also sequenced for inclusion as

121 outgroups. Where sequences from these outgroups could not be obtained (i.e. due to non-

122 amplification), alternative sequences were retrieved from GenBank (details in Table S1).

123 Sequences obtained in this study were deposited in GenBank under accession numbers

124 KX669691-KX670093, KX753349.

125

126

127

Table 2. Number of Tenuibranchiurus specimens analysed for each gene fragment from each of the sampled localities, as well as outgroup sequences included (see Table S1 for sequence details).

\begin{tabular}{|c|c|c|c|c|c|c|c|}
\hline \multirow[t]{2}{*}{ State } & \multirow{2}{*}{ General Locality } & \multirow{2}{*}{ Location ID } & \multicolumn{5}{|c|}{ Number of specimens analysed } \\
\hline & & & $\mathrm{COI}$ & $16 \mathrm{~S}$ & GAPDH & $\mathrm{H} 3$ & $\mathrm{AK}$ \\
\hline \multirow[t]{23}{*}{ Qld } & Kinkuna National Park & KNP & - & 1 & - & - & - \\
\hline & Hervey Bay & $\mathrm{HB}$ & 1 & 4 & - & 4 & 4 \\
\hline & Maryborough & MAR & 10 & 5 & 9 & 5 & 3 \\
\hline & Tuan State Forest (North) & TSFN & 2 & 2 & - & - & - \\
\hline & Tuan State Forest (South) & TSFS A & 4 & 1 & 4 & 1 & 1 \\
\hline & & $\mathrm{C}$ & 14 & 3 & 12 & 4 & 4 \\
\hline & & $\mathrm{E}$ & 4 & 2 & 4 & 2 & 2 \\
\hline & & $\mathrm{F}$ & 3 & 1 & 3 & 1 & 1 \\
\hline & & $\mathrm{G}$ & 4 & - & 4 & - & - \\
\hline & & $\mathrm{H}$ & 1 & - & 1 & - & - \\
\hline & Tewantin & TEW & 7 & 3 & 7 & 4 & 4 \\
\hline & Lake Weyba & LW & 7 & 4 & 7 & 5 & 4 \\
\hline & Eumundi & $\mathrm{Eu}$ & - & 1 & - & - & - \\
\hline & Mooloolaba & Moo & - & 1 & - & - & - \\
\hline & Beerburrum & BER & 7 & 2 & 5 & 2 & 2 \\
\hline & Type Locality & TL1 & - & 1 & 1 & - & - \\
\hline & & TL2 & - & 2 & 1 & 1 & 1 \\
\hline & & TL3 & 1 & 2 & - & - & - \\
\hline & Bribie Island & BRB1 & - & - & 1 & - & - \\
\hline & & $\mathrm{BRB} 2$ & 4 & - & - & - & - \\
\hline & & $\mathrm{BRB}$ & 6 & 6 & - & 6 & 6 \\
\hline & Gold Coast & $\mathrm{GC} 1$ & 8 & 3 & 5 & 5 & 3 \\
\hline & & $\mathrm{GC} 2$ & 7 & 3 & 6 & 4 & 3 \\
\hline \multirow[t]{4}{*}{ NSW } & Lennox Head & $\mathrm{LH}$ & 13 & 4 & 10 & 4 & 3 \\
\hline & Broadwater National Park & BNP1 & 13 & 4 & 9 & 4 & 2 \\
\hline & & BNP2 & 2 & 1 & 2 & 1 & - \\
\hline & Lake Hiawatha & LakeH & 9 & 3 & 4 & 5 & 4 \\
\hline & Total & & 127 & 59 & 95 & 58 & 47 \\
\hline & Gramastacus spp. & & 6 & 10 & 4 & 7 & 4 \\
\hline & Geocharax spp. & & 3 & 4 & 3 & 1 & 1 \\
\hline & Engaeus spp. & & 2 & 2 & 2 & 3 & 1 \\
\hline & Engaewa spp. & & 3 & 3 & 3 & 3 & 2 \\
\hline & Cherax spp. & & 1 & 1 & 1 & 1 & - \\
\hline & Total including outgroups & & 142 & 79 & 108 & 73 & 55 \\
\hline
\end{tabular}


Degree of molecular divergence

132 Preliminary analyses of both individual and combined gene trees showed a prominent separation

133 between Qld and NSW populations. In light of this, genetic distances between Qld and NSW

134 populations, distances between these two groups and the outgroups, and distances between the

135 outgroups were calculated using both COI and 16S data to compare the degree of separation.

136 These distances were calculated in MEGA5 (Tamura et al. 2011) using the net between group

137 mean distances with 1000 bootstrap replicates (gamma distribution with shape parameter $=1$,

138 Maximum Composite Likelihood (MCL) model; positions containing gaps and missing data

139 were eliminated).

141 Species Discovery Approaches

142 Two types of analyses were used to obtain a best-estimate of the species-level lineages present

143 within Tenuibranchiurus; namely, groupings identified through use of a concatenated alignment

144 phylogeny (referred to henceforth as the 'combined gene tree'), and intra- versus inter-cluster

145 variation through $\Phi_{\mathrm{ST}}$ analysis. A combined gene tree analysis was chosen over individual gene

146 trees because, although preliminary phylogenetic analyses performed on the individual gene

147 regions suggested that there were multiple genetic groups within $T$. glypticus, statistical support

148 was not always strong for all genes. Therefore, in order to increase the strength of the

149 phylogenetic signal, and thus support for branching patterns, the five gene alignments were

150 concatenated and analysed as a single data set for phylogenetic reconstructions.

151

152 Combined gene tree

153 Combined gene trees were inferred using both Maximum Likelihood (ML) and Bayesian

154 analyses. Specimens were included in the data set if they were sequenced for at least four of the

155 five genes (see Table S1). The program RAxML v. 7.4.4 through the CIPRES Science Gateway

156 (Miller et al. 2010) was used to infer the ML tree, and MrBayes v. 3.2.0 (Ronquist et al. 2012)

157 for the Bayesian tree. Within the ML analysis, each gene was entered as a separate DNA-

158 partition, the GTR+CAT model used, and bootstrapping automatically halted with the majority

159 rule criterion. For the Bayesian analysis, each gene was entered as a separate partition with the

160 Nst set as 6 for all genes except 16S (where Nst =2), and Rates set as InvGamma for COI and

161 GAPDH, and Gamma for 16S, H3, and AK, as determined by jModeltest v. 0.0.1 (Posada 2008).

162 Additional parameters were set as follows; two replicate Markov chain Monte Carlo analyses 
163 with four chains in each analysis (one cold, three heated), the statefreq, revmat, shape, and pinvar

164 all unlinked, the ratepr set as variable, and the analysis set to stop when the standard deviations

165 of the partition frequencies $<0.0099$ (all effective sample size values $>100$, PSRF $+\approx 1.000$, and

166 the final Ngen was $1,715,000)$. The same analysis was performed at least twice to verify

167 topological convergence and homogeneity of posterior clade probabilities between runs. The

168 first $25 \%$ of samples were discarded as burnin, with the resulting trees visualised using the

169 program Figtree v. 1.4.0 (Rambaut 2012).

170

171 Intra- versus inter-cluster variation

172 An analysis of molecular variance (AMOVA) was used to calculate variation within and among

173 clusters of sequences, as implemented in Arlequin v. 3.1 (Excoffier et al. 2005). To determine

174 what the most likely lineages were, the clades identified by the combined gene tree analysis, as

175 well as additional splits evident within the tree that were deemed to plausibly represent lineages,

176 were also tested, as well as groups based on the geographic division of populations (i.e.

177 collection locality; see Table S2). The AMOVA calculates three statistics; $\Phi_{\mathrm{ST}}, \Phi_{\mathrm{SC}}$, and $\Phi_{\mathrm{CT}}$, all

178 of which are based on both the haplotype frequency and genetic divergence. $\Phi_{\mathrm{ST}}$ measures

179 variation among all populations, and $\Phi_{\mathrm{SC}}$ measures variation among populations within groups,

180 and $\Phi_{\mathrm{CT}}$ estimates variation among groups. It has been suggested that an $\mathrm{F}_{\mathrm{CT}}$ value $>0.95$ can

181 represent evidence for accurate species groupings (i.e. $>95 \%$ of the genetic variation can be

182 attributed to differences among groups) (Monaghan et al. 2005). Using the $\Phi_{\mathrm{CT}}$ estimate as a

183 surrogate for $\mathrm{F}_{\mathrm{CT}}$ (as this estimate includes genetic divergence as well as haplotype frequency),

184 this can provide an approach to delineate taxa based on population genetic analyses by

185 interpreting the AMOVA results used to calculate intra- versus inter-cluster variation in a way

186 analogous to F-statistics (Wright 1978). The criterion to determine the appropriate number of

187 lineages using this method is where an increase in the number of suggested lineages does not

188 appreciably increase the $\Phi_{\mathrm{CT}}$ estimate for those lineages.

\section{Validation of Lineages}

191 In order to validate the lineages that were identified using the species discovery approaches for 192 species-status, two methods were used; barcoding gap identification (sensu Hebert et al. 2004), 193 and the K/ $\theta$ method (sensu Birky 2013). These two methods were chosen as they both test 
194 species boundaries by comparison of intra- and inter-lineage differences, but do so in different 195 ways; thus allowing the results of each method to be tested and validated by the other. Only the 196 mitochondrial data were used to validate the species hypotheses, as the nuclear gene sample sizes

197 were limited and individually were not very informative; for instance, most of the nuclear gene 198 trees contained numerous polytomies and thus could not be used to identify genetically divergent 199 groups.

200

201

\section{Barcoding gap}

202 The genetic distances between the hypothesised lineages and between specimens for both COI 203 and $16 \mathrm{~S}$ were calculated and visualised to determine whether a barcoding gap existed. As the intent of this method was to provide support for, or refutation of, the lineage hypotheses formed through the species discovery approaches, lineages were pre-defined based on those results and genetic distances categorised as representing either intra- or inter-lineage distances. For the purposes of this study, a barcoding gap was defined as a clear separation (or 'gap') between the highest intra-lineage and lowest inter-lineage genetic distances measured between the suggested lineages. Although a standard threshold has been suggested by Hebert et al. (2004) for recognising distinct species $(10 \times$ average intraspecific difference), this approach was not followed as it has been shown that there are vastly different rates of divergence for both different taxa and different genetic markers (Avise 2009). Rather, a recognisable distinction between the inter- and intra-lineage distances was considered potential evidence for distinct species. Analyses were undertaken for Qld and NSW specimens separately.

Relative divergences between genetic groups were calculated in MEGA5. To determine interlineage divergence, the number of base substitutions per site was estimated from the net average between groups of sequences and the diversity between specimens was determined by calculating the number of base substitutions per site between each sequence, both using a MCL model with 1000 bootstrap replicates. The rate variation among sites was modelled with a gamma distribution with a shape parameter of 1, with positions containing gaps and missing data

222 eliminated. This was performed separately for both COI and 16S, with all unique haplotypes 
$225 \underline{\mathrm{K} / \theta \text { Method }}$

226 The species discovery hypotheses were also tested using the K/ $\theta$ method (Birky et al. 2010;

227 Birky \& Barraclough 2009; Birky et al. 2005). Although this method was originally developed

228 for asexually-reproducing organisms and termed the $4 \mathrm{X}$ rule, it has been further developed and

229 shown to be effective for the mtDNA region for sexually-reproducing organisms (Birky 2013).

230 This method provides a simple way of defining species groups based on specimens/populations

231 that form clusters (i.e. clades) that are separated by genetic gaps too deep to be ascribed to

232 random genetic drift within a species and, therefore, must be due to diversifying selection or

233 long-term physical isolation (Apte et al. 2007).

234

235 Using the groups from the species discovery hypotheses, sister clades were identified and

236 statistical support for these was tested. Sequence divergences were estimated within (d) and

237 between each sister clade using uncorrected p-distances calculated in MEGA5. Nucleotide

238 diversity $(\pi)$ was then calculated using $\pi=\ln /(n-1)$, where $n$ is the number of samples per clade.

239 Theta $(\theta)$ was then estimated as $\theta=2 \mathrm{Ne} \mu$ (where $\mathrm{Ne}$ is the effective populations size and $\mu$ is

240 mutation rate per base pair per generation) by calculating $\pi /(1-4 \pi / 3)$ within each clade. If $d=0$

241 (as it did for one clade in this study), then $\pi$ can alternatively be calculated as $2 / \mathrm{Ln}(\mathrm{n}-1)$, where $\mathrm{L}$

242 is the length of the sequence. K was then calculated for each sister-clade comparison (using

243 MEGA5) as the uncorrected net between group mean distance, with this divided by the highest $\theta$

244 in the comparison (as this is the more conservative approach) to provide $\mathrm{K} / \theta$. Where sister

245 clades were poorly defined in the tree, $\mathrm{K}$ was estimated between all potential sister clades in the

246 polytomy, with the clade of the lowest K considered to be the sister clade. Finally, following the

247 method of Birky (2013), if the K/ $\theta$ value was greater than 4, then the sister clades were accepted

248 as different lineages. 
251 RESULTS

252 Degree of Molecular Divergence

253 The genetic distances calculated between the Qld and NSW groups using COI and 16S were

$25416.0 \%$ and $12.7 \%$, respectively (Table 3). These distances were as large as, or in some cases

255 larger than, the distances calculated between these two groups and other closely related genera.

256 Furthermore, some distances between pairs of the other genera were smaller than those between

257 the Qld and NSW groups for both COI and 16S (e.g. Geocharax versus Engaeus $=13.7 \%$ and

$258 \quad 6.7 \%$, Gramastacus versus Engaeus $=11.7 \%$ and 8.1\%; Table 3).

259

260 Table 3. Estimates of net evolutionary divergence between groups of COI (below diagonal) and 16S

261 (above diagonal) sequences with a MCL model.

\begin{tabular}{cccccccc}
\hline & Qld & NSW & Geocharax & Gramastacus & Engaeus & Engaewa & Cherax \\
\hline Qld & - & 0.127 & 0.14 & 0.161 & 0.101 & 0.175 & 0.24 \\
NSW & 0.160 & - & 0.113 & 0.117 & 0.072 & 0.191 & 0.24 \\
Geocharax & 0.156 & 0.164 & - & 0.129 & 0.067 & 0.212 & 0.257 \\
Gramastacus & 0.185 & 0.206 & 0.203 & - & 0.081 & 0.244 & 0.242 \\
Engaeus & 0.109 & 0.086 & 0.137 & 0.117 & - & 0.138 & 0.189 \\
Engaewa & 0.164 & 0.154 & 0.160 & 0.169 & 0.103 & - & 0.347 \\
Cherax & 0.256 & 0.256 & 0.261 & 0.294 & 0.195 & 0.228 & - \\
\hline
\end{tabular}

262

263 Species Discovery

264 Groups that are identified as potentially representing distinct species will be referred to herein as

265 Lineages, and will form the groups to be analysed through lineage validation methods.

266

267 Combined gene tree

268 Although not all groupings were statistically supported, both the ML and Bayesian combined

269 gene trees suggested the presence of multiple groups within Qld and NSW, and displayed the

270 same topologies (Fig. 2). Six clades were evident within the Qld populations, with the

271 monophyly of all but two highly supported (as these were represented by single specimens). The

272 first clade included Maryborough and some Tuan State Forest specimens (Lineage 1; BS 90\%,

273 Pp 1), and the second contained the remaining Tuan State Forest specimens as well as Bribie

274 Island, Type Locality, and some Beerburrum specimens (Lineage 2; BS 96\%, Pp 1). The two

275 groups for which monophyly could not be established were represented by the remaining

276 Beerburrum specimens (Lineage 3) and Hervey Bay (Lineage 4). The final two clades consisted

277 of Tewantin and Lake Weyba specimens (Lineage 5; BS 100\%, Pp 1) and Gold Coast specimens 
278 (Lineage 6; BS 100\%, Pp 1). There was also some geographic structuring evident within each of 279 the clades.

280

281 The two monophyletic clades evident within the NSW populations were strongly supported, and

282 form Lineage 7 (Lennox Head) and Lineage 8 (Lake Hiawatha, Broadwater National Park 1 \& 2)

283 (Fig. 2). Although there was some structuring evident within Lineage 8, the branching patterns

284 were very shallow and were therefore not explored as potential distinct lineages. 


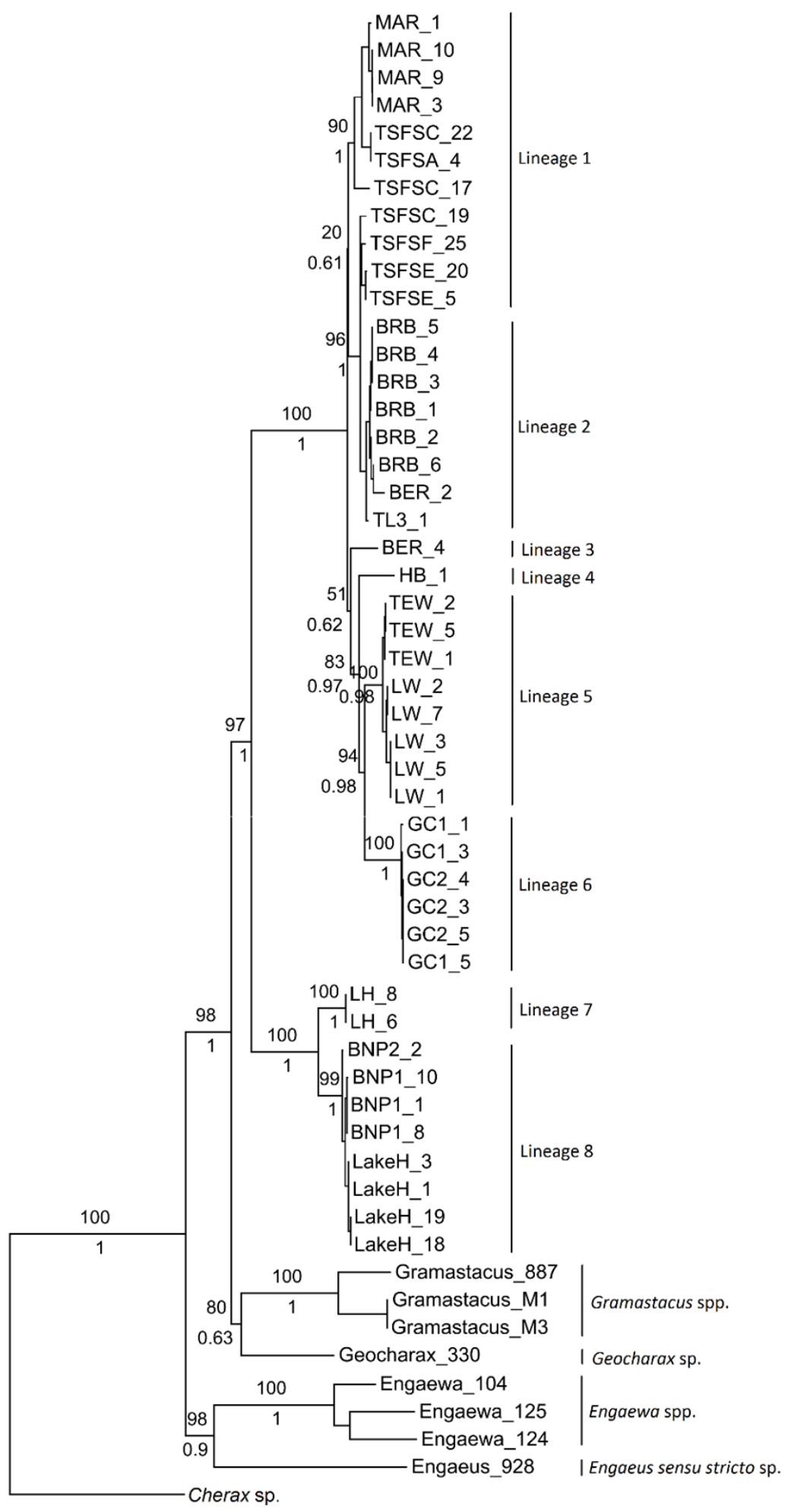

287 Figure 2. Maximum likelihood phylogeny showing the proposed lineages for Queensland (Lineages 1 288 through 6) and New South Wales (Lineages 7 and 8). Bootstrap values from the maximum likelihood 
289

290

291

292

293

294

295

296

297

298

299

300

301

302

analysis are shown above the branches, and posterior probabilities from the Bayesian analysis are shown below branches for the major nodes, as both analyses produced identical topologies for the major nodes.

\section{Intra- versus inter-cluster variation}

A total of eight lineage arrangements was deemed plausible based on apparent genetic groupings and collection localities, and were tested using AMOVAs (Table 4). The process of assigning the potential lineages is outlined in Table S2, where a hierarchical approach was taken to split the tree into major genetic groups, minor genetic groups, and geographic localities. As there was no logical reason for combining the NSW lineages for the AMOVA analysis based on either the phylogenetic or geographic information, the NSW populations were considered to consist of the LH lineage and the LakeH/BNP lineage. Further testing, however, was considered appropriate to determine the lineages present within Qld. Figure 3 shows an increase in the $\Phi_{\mathrm{CT}}$ estimate, with a plateau reached at six lineages for both the COI and 16S estimates. These six Qld lineages represent the most parsimonious arrangement of the specimens into lineages.

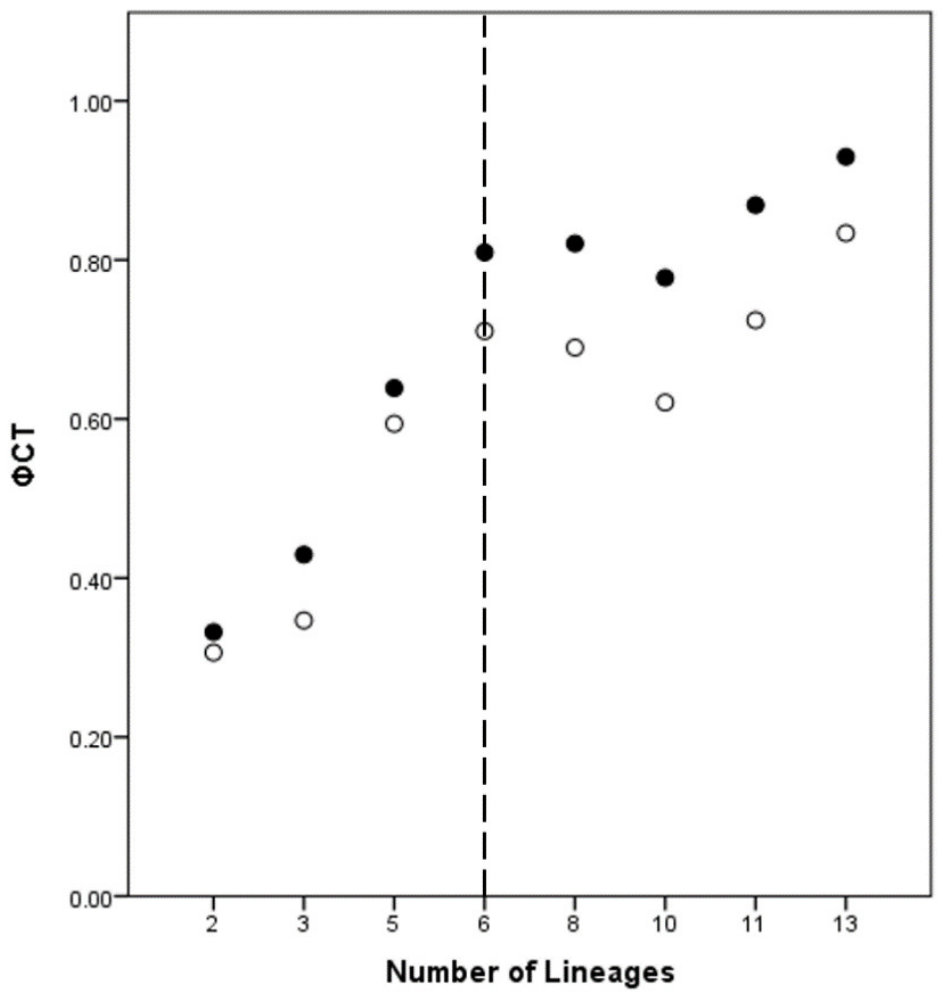

303

304 305
Figure 3. $\Phi_{\mathrm{CT}}$ values for potential lineages for both COI (open circles) and 16S (black circles) for Queensland specimens. The dotted line indicates the most likely delimitation at six lineages. 
308 Table 4. Summary of possible lineages based on $\Phi$-statistics for Qld specimens using COI and 16S data.

309 See Table S2 for explanation of how potential lineages were determined. Where specimens from the

310 same collection locality are split into two or more groups, details are included below the table for

311 clarification.

\begin{tabular}{|c|c|c|c|c|c|c|c|c|}
\hline \multirow{2}{*}{ Location ID } & \multicolumn{8}{|c|}{ Number of potential lineages } \\
\hline & 2 & 3 & 5 & 6 & 8 & 10 & 11 & 13 \\
\hline \multicolumn{9}{|l|}{ MAR } \\
\hline \multicolumn{9}{|l|}{ TSFN } \\
\hline \multicolumn{9}{|l|}{ TSFSA $^{\mathrm{a}}$} \\
\hline \multicolumn{9}{|l|}{ TSFSC $^{b}$} \\
\hline \multicolumn{9}{|l|}{ TSFSA } \\
\hline \multicolumn{9}{|l|}{ TSFSC } \\
\hline \multicolumn{9}{|l|}{ TSFSE } \\
\hline \multicolumn{9}{|l|}{ TSFSF } \\
\hline \multicolumn{9}{|l|}{ TSFSG } \\
\hline \multicolumn{9}{|l|}{ TSFSH } \\
\hline \multicolumn{9}{|l|}{ TL } \\
\hline \multicolumn{9}{|l|}{$\mathrm{BRB}$} \\
\hline \multicolumn{9}{|l|}{$\mathrm{BER}^{\mathrm{c}}$} \\
\hline \multicolumn{9}{|l|}{$\mathrm{BER}^{\mathrm{d}}$} \\
\hline \multicolumn{9}{|l|}{$\mathrm{HB}$} \\
\hline \multicolumn{9}{|l|}{ LW } \\
\hline \multicolumn{9}{|l|}{ TEW } \\
\hline \multicolumn{9}{|l|}{ GC1 } \\
\hline \multicolumn{9}{|l|}{$\mathrm{GC} 2$} \\
\hline $\mathrm{COI}-\Phi_{\mathrm{SC}}$ & 0.75848 & 0.73003 & 0.62052 & 0.40768 & 0.39226 & 0.49189 & 0.30985 & 0.16883 \\
\hline $\mathrm{COI}-\Phi_{\mathrm{ST}}$ & 0.83245 & 0.82362 & 0.84592 & 0.82845 & 0.81145 & 0.80721 & 0.80969 & 0.80564 \\
\hline $\mathrm{COI}-\Phi_{\mathrm{CT}}$ & 0.30627 & 0.34669 & 0.59395 & 0.71038 & 0.68975 & 0.62057 & 0.72424 & 0.83371 \\
\hline $16 \mathrm{~S}-\Phi_{\mathrm{SC}}$ & 0.87218 & 0.84538 & 0.77989 & 0.53957 & 0.47467 & 0.56598 & 0.24716 & 0.43330 \\
\hline $16 \mathrm{~S}-\Phi_{\mathrm{ST}}$ & 0.91463 & 0.91177 & 0.92051 & 0.91225 & 0.90574 & 0.90342 & 0.90123 & 0.89906 \\
\hline $16 \mathrm{~S}-\Phi_{\mathrm{CT}}$ & 0.33209 & 0.42938 & 0.63887 & 0.80942 & 0.82056 & 0.77748 & 0.86880 & 0.92958 \\
\hline
\end{tabular}

317 Species discovery hypothesis

318 As the combined gene tree was inferred using only specimens that were successfully sequenced

319 for at least four of the five genes, not all collection localities were represented on the tree (i.e.

320 TSFN, KNP, Moo, Eu). Of these localities, only TSFN was represented in the AMOVA

321 analysis, as the remaining localities were represented by a single sequence and therefore could

322 not be included in the AMOVA. In order to assign these populations to a lineage for further

323 testing, the individual gene trees and haplotype networks were examined and the localities were

324 designated through the closest phylogenetic connection (data not shown). Both of the species

325 discovery approaches suggested the presence of eight lineages (six in Qld and two in NSW;

326 Table 5), and formed the lineages to be validated. 
329 Table 5. Lineages assigned through two species discovery approaches and the final lineage hypothesis, for 330 Queensland and New South Wales localities. Dashes indicate where a population was not included.

\begin{tabular}{cccc}
\hline Location ID & Combined gene tree & AMOVA & Lineage hypothesis \\
\hline KNP & - & - & \\
TSFN & - & Lineage 1 & Lineage 1 \\
MAR & Lineage 1 & - & \\
TSFS & - & & \\
\hline Moo & & Lineage 2 & Lineage 2 \\
TSFS & Lineage 2 & & \\
TL & & Lineage 3 & Lineage 3 \\
BRB & Lineage 3 & Lineage 4 & Lineage 4 \\
BER & Lineage 4 & Lineage 5 & Lineage 5 \\
\hline BER & Lineage 5 & - & Lineage 6 \\
\hline HB & - & Lineage 6 & Lineage 7 \\
\hline TEW & Lineage 6 & Lineage 7 & Lineage 8 \\
Eu & Lineage 7 & Lineage 8 & \\
\hline GC & Lineage 8 & & \\
\hline LH & & &
\end{tabular}

331

\section{Validation of Lineages}

333 Barcoding gap

334 The COI data showed some overlap of the intra- and inter-lineage estimates within Qld, resulting

335 in no usable barcoding gap for lineage separation (Fig. 4A). Where the overlap occurred, the

336 low inter-lineage estimates were attributable to the Lineage 1 vs. Lineage 2 comparison, and the

337 high intra-lineage estimates were seen between specimens within Lineage 1. However, many

338 estimates between these two lineages fell in the higher range of the inter-lineage estimates as

339 well as the low range.

341 The 16S data for Qld populations showed a clearer relationship between lineages (Fig. 4C).

342 Although there was a very small overlap between the intra- and inter-lineage distances

343 (occurring between two specimens from Lineage 1), this represented an overlap of less than

$3440.01 \%$. When the existence of this overlap was disregarded, there was a small gap at $2.8-3.0 \%$.

345 However, despite there not being a distinguishable gap due to the overlap, identification of the

346 majority of lineages through the comparison of intra- and inter-lineage distances was clear and

347 distinguishable.

When the estimates within and between Lineage 1 and 2 specimens were removed from both the

$\mathrm{COI}$ and $16 \mathrm{~S}$ data (with the comparison between these two lineages and all other lineages 
351 remaining), a clear barcoding gap was seen in both data sets (Fig. 4B,D). For COI, the gap

352 occurred between $1.7-4.7 \%$, and between $0.9-3.5 \%$ for $16 \mathrm{~S}$. This shows that all other Qld groups

353 (i.e. Lineage 3 through 6) represent clear lineages based on the barcoding approach using both

354 COI and 16S data.

355

356 For NSW populations, there was a clear barcoding gap between the two lineages (i.e. Lineage 7

357 and 8), occurring between 1.5-6.6\% for the COI data and 0.7-3.0\% for the $16 \mathrm{~S}$ data (Fig. 5).
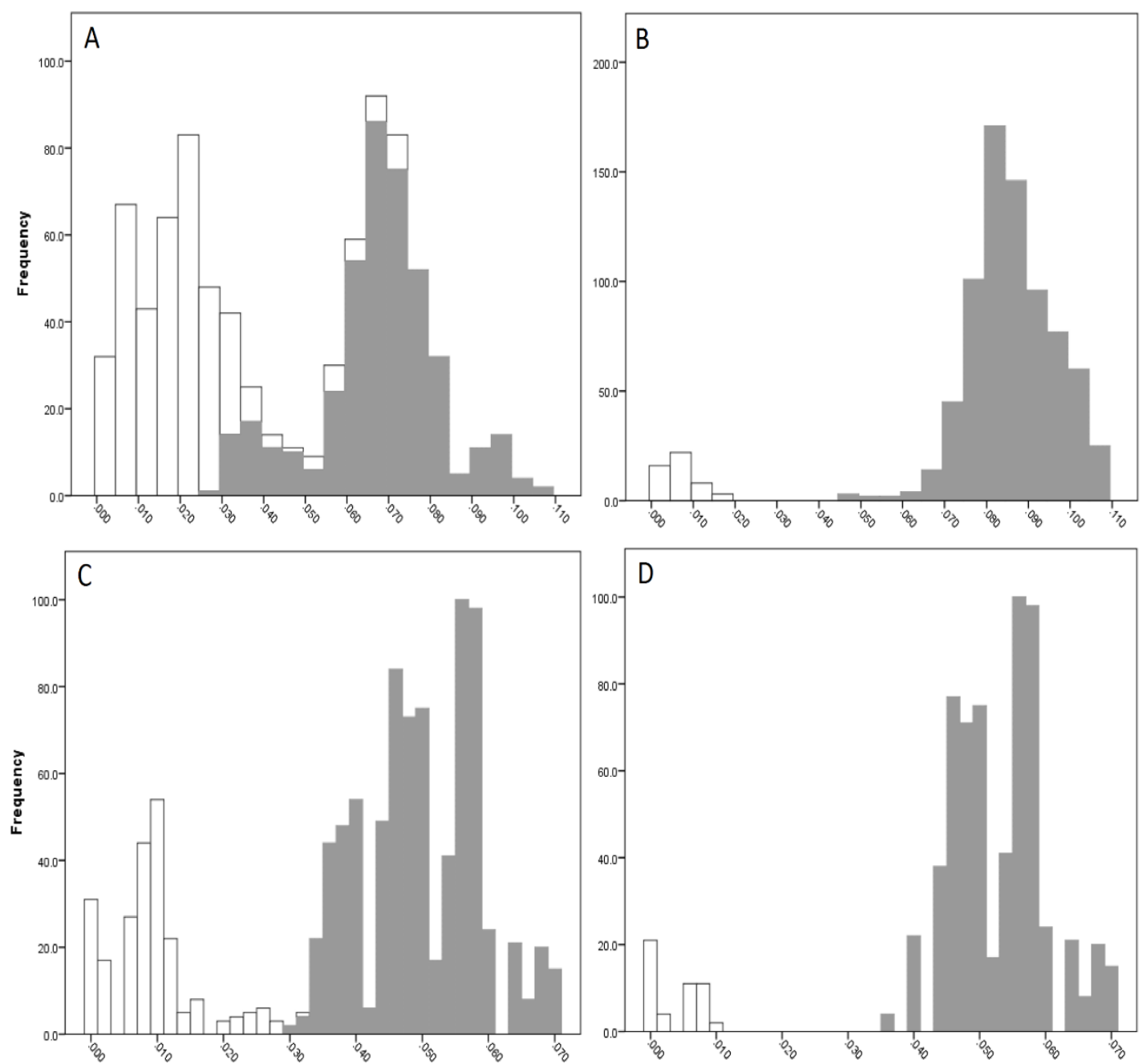

Figure 4. Intra- and inter-lineage genetic distance estimates (white and grey, respectively) for Queensland lineages showing (A) COI estimates for all lineages, (B) COI estimates without comparisons between 

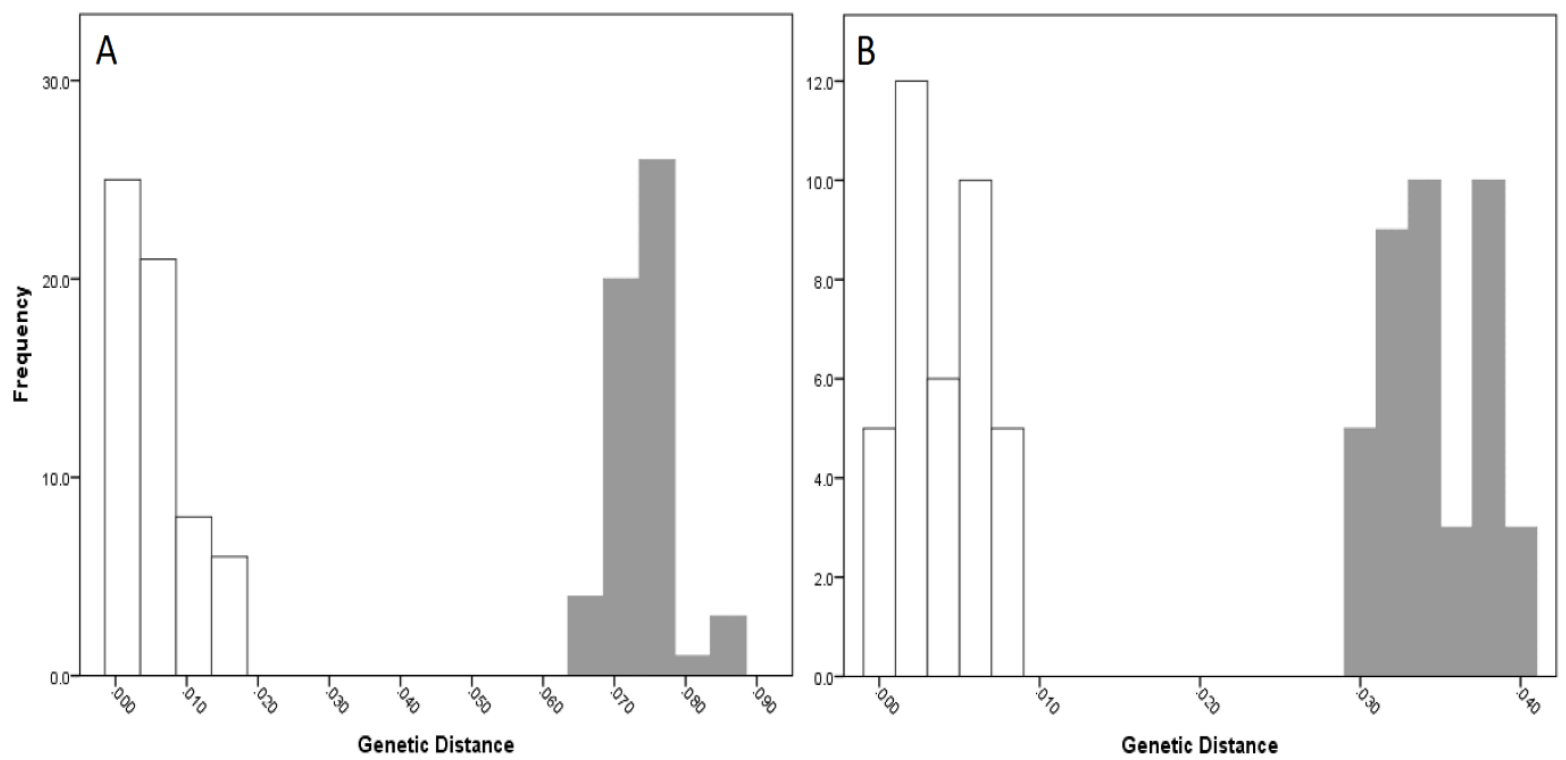

364

365

366

367

368

369

370

371

372

373

374

375

376

377

Figure 5. Intra- and inter-lineage genetic distance estimates (white and grey, respectively) for New South Wales lineages showing (A) COI and (B) 16S estimates for all lineages

\section{$\underline{\mathrm{K} / \theta \text { method }}$}

The sister clades within Qld and NSW were tested using the $\mathrm{K} / \theta$ method for a delimitation of eight lineages (six from Qld, two from NSW) using both COI and $16 \mathrm{~S}$ data (Table 6). In some instances, sister clades that were defined by the lowest K-distance (as they were ambiguous based on the combined gene tree) differed between the COI and $16 \mathrm{~S}$ datasets. In these cases, only the relevant $\mathrm{K} / \theta$ comparison for the applicable gene was calculated.

Table 6. K/ $\theta$ values for both COI and $16 \mathrm{~S}$ for comparisons between sister clades within Queensland and New South Wales. Where specimens from the same collection locality are split into two or more lineages, details are included below the table for clarification. Dashes are used where sister clades differ between $\mathrm{COI}$ and $16 \mathrm{~S}$.

\begin{tabular}{cccc}
\hline \multirow{2}{*}{ Sister Clade 1 } & \multirow{2}{*}{ Sister Clade 2 } & \multicolumn{2}{c}{ K// } \\
& COI & 16S \\
\hline Lineage 1 & Lineage 2 & 0.78 & 1.41 \\
Lineage 2 & Lineage 1 & 0.78 & 1.41 \\
Lineage 3 & Lineage 1 & - & 1.67 \\
\hline & Lineage 5 & 6.99 & - \\
Lineage 4 & Lineage 5 & 7.18 & - \\
\hline & Lineage 6 & - & 32.84 \\
\hline Lineage 5 & Lineage 6 & 6.71 & - \\
\hline & Lineage 2 & - & 4.92 \\
Lineage 6 & Lineage 5 & 6.71 & 8.24 \\
\hline Lineage 7 & Lineage 8 & 16.03 & 6.48 \\
Lineage 8 & Lineage 7 & 16.03 & 6.48 \\
\hline
\end{tabular}

Lineage $1=$ MAR\&TSFN\&TSFSA (specimen 4) \&TSFSC (specimens 8,17,22)

Lineage $2=$ TSFSA-H (specimens 1-3,5-7,9-12,14,16,18-21,23-30) \& BRB \& TL \& BER (specimens $1,2,5)$

Lineage $3=$ BER (specimens $3,4,6,7$ ) 


\section{Lineage assignment}

380 Although there was some ambiguity in the barcoding analysis of the Qld COI data regarding the

381 separation of Lineage 1 and 2, the 16S data showed support for the species discovery lineage

382 hypothesis. Because of the deeper phylogenetic inferences provided by $16 \mathrm{~S}$ in addition to the

383 fact that there were many genetic distances within and between Lineage 1 and 2 falling within

384 the expected distributions, the lineage hypothesis for Qld populations was considered supported

385 by this analysis (Table 7). The two NSW lineages were clearly separate based on both the COI

386 and $16 \mathrm{~S}$ data and were therefore also supported (Table 7). In the K/ $\theta$ analysis, all lineages were

387 supported by both genes with the exception of the split between Lineage 1 and 2 (both genes),

388 and Lineage 1 and 3 (16S) (Table 7).

Table 7. The species discovery lineage hypothesis and two lineage validation methods, with the final assignment of lineages for Queensland and New South Wales localities. Dashes indicate where a

392 population was not included.

\begin{tabular}{|c|c|c|c|c|}
\hline Location ID & Lineage hypothesis & Barcoding gap & $\mathrm{K} / \theta$ & $\begin{array}{c}\text { Final lineage } \\
\text { assignment }\end{array}$ \\
\hline KNP & \multirow[b]{2}{*}{ Lineage 1} & \multirow[b]{2}{*}{ Lineage 1} & - & \multirow[b]{2}{*}{ Lineage 1} \\
\hline $\begin{array}{l}\text { TSFN } \\
\text { MAR } \\
\text { TSFS }\end{array}$ & & & Lineage $1 / 2$ & \\
\hline Moo & \multirow{5}{*}{ Lineage 2} & \multirow{5}{*}{ Lineage 2} & - & \multirow{5}{*}{ Lineage 2} \\
\hline TSFS & & & - & \\
\hline $\mathrm{TL}$ & & & \multirow{3}{*}{ Lineage $1 / 2$} & \\
\hline $\mathrm{BRB}$ & & & & \\
\hline BER & & & & \\
\hline BER & Lineage 3 & Lineage 3 & Lineage 3 & Lineage 3 \\
\hline HB & Lineage 4 & Lineage 4 & Lineage 4 & Lineage 4 \\
\hline TEW & \multirow{3}{*}{ Lineage 5} & \multirow{3}{*}{ Lineage 5} & Lineage 5 & \multirow{3}{*}{ Lineage 5} \\
\hline LW & & & & \\
\hline $\mathrm{Eu}$ & & & - & \\
\hline $\mathrm{GC}$ & Lineage 6 & Lineage 6 & Lineage 6 & Lineage 6 \\
\hline $\mathrm{LH}$ & Lineage 7 & Lineage 7 & Lineage 7 & Lineage 7 \\
\hline $\begin{array}{c}\text { BNP } \\
\text { LakeH }\end{array}$ & Lineage 8 & Lineage 8 & Lineage 8 & Lineage 8 \\
\hline
\end{tabular}


395

396

397

398

399

400

401

402

403

404

405

406

407

408

409

410

411

412

413

414

415

416

417

418

419

420

421

422

423

424

425

\section{DISCUSSION}

\section{Phylogenetic Relationships}

Based on a preliminary data set, Dawkins et al. (2010) highlighted the presence of two genetically divergent groups within Tenuibranchiurus and from this suggested the potential presence of two distinct species within the genus. The phylogenetic reconstruction of this study supports the presence of these two divergent groups; however, the larger data set used, as well as the additional nuclear genes analysed, suggests that the recognition of the two groups should be at a generic, rather than specific, level. Inclusion of the most closely-related genera (i.e. Gramastacus, Geocharax, Engaeus, and Engaewa) in the analyses shows that the genetically divergent entities represented by the Qld and NSW groups each form monophyletic clades, to the exclusion of all other genera. While the splitting of a monophyletic grouping into two genera is arguably arbitrary, the degree of divergence suggests it is warranted in this case. The only other studies to suggest a novel parastacid genus based on molecular analyses were undertaken by Schultz et al. (2007) and Hansen \& Richardson (2006). The study of Schultz et al. (2007) proposed a potential new genus (which was simply referred to as E. lyelli, as Engaeus lyelli was the only species in the divergent lineage) based on it being a highly divergent lineage within their phylogeny and found support for this through comparisons of genetic distances, in a similar fashion to this study. However, the validity of this genus was never thoroughly tested, nor were the authors confident that complete taxon sampling had been achieved. Hansen and Richardson (2006) included molecular data in their rationale for erecting two new genera (Spinastacoides and Ombrastacoides), but simply stated that their criteria for recognition of a genus was "a substantial degree of genetic difference, either in the $16 \mathrm{~S}$ data or in the allozyme data", combined with support from their morphological data (Hansen \& Richardson 2006, pg 719). As such, due to the widespread and extensive collecting undertaken and the application of methods to identify and test lineage hypotheses employed in this study, it is the first to propose and validate the presence of a novel parastacid genus using a systematic and thorough testing of molecular data.

Although it is difficult to define what degree of separation is necessary between genera at a molecular level (Rach et al. 2008), based on the genetic distances presented in this study there is strong support for division at genus level. For instance, the genetic distance between Qld and 
426 NSW populations is larger than that seen between Engaeus and both Geocharax and

427 Gramastacus for the COI and 16S gene fragments, and between Engaewa and both Geocharax

428 and Engaeus for COI. Other genera also show smaller genetic distances when compared to

429 either Q1d or NSW than these two groups do with each other. Regardless of which genera were

430 genetically closer to each other, the distance between Qld and NSW is at least as large as those

431 between existing genera (Table 3), thereby supporting their separation into two distinct genera.

432

433 Species Identification

434 Both of the species discovery approaches established the presence of the same eight lineages

435 across Qld and NSW specimens of Tenuibranchiurus. Of these, Lineages 3 through 8 were

436 highly supported by the two lineage validation methods used. However, support for the

437 distinction between Lineages 1 and 2 was dependent upon the method and gene used. Using the

438 barcoding approach, it has been found that recently-diverged species are harder to distinguish

439 than older species (Lou \& Golding 2010; Meyer \& Paulay 2005; Yassin et al. 2010), with

440 problems most likely attributable to incomplete lineage-sorting resulting in the lack of a

441 barcoding gap (van Velzen et al. 2012). Additionally, when using both the barcoding and K/ $\theta$

442 methods, the high levels of genetic diversity found within each lineage (rather than low levels

443 between them) may have resulted in these two lineages not being strongly supported.

444 Alternatively, retained ancestral variation between two recently-diverged clades may mask their

445 current genetic isolation using the $\mathrm{K} / \theta$ method, as divergence will follow a continuum and

446 therefore no single percentage will work in every case (Druzhinina et al. 2012). Although this

447 method has proven useful for other studies of sexually-reproducing organisms (e.g. Leasi et al.

448 2013; Marrone et al. 2010; Reniers et al. 2013), the results presented here suggest that it may not

449 be suitable for delineating between some species where intraspecific diversity is high. In light of

450 this, and considering the support shown by the species discovery lineages suggested and the

451 barcoding results, Lineage 1 and 2 are accepted as independently evolving lineages and,

452 therefore, putative species.

453

454 Based on our results, the genus Tenuibranchiurus is represented only by specimens collected

455 from Queensland. As such, Tenuibranchiurus glypticus remains a valid species and it is

456 represented by populations grouped with samples from the Type Locality. Five new putative 
457 species were identified within Tenuibranchiurus (Table 8). Specimens collected from New

458 South Wales belong to a putative newly-proposed genus with two new putative species (Table

459 8). Until a formal description is completed, the new genus will be referred to as Gen. nov..

460

461 Table 8. Existing and putative species identified within Tenuibranchiurus and the newly proposed Gen. 462 nov..

\begin{tabular}{cc}
\hline Species & Location \\
\hline & Kinkuna National Park \\
Tenuibranchiurus sp. nov. 1 & $\begin{array}{c}\text { Tuan State Forest North } \\
\text { Maryborough } \\
\text { Tuan State Forest South }\end{array}$ \\
\hline & Mooloolaba \\
& Tuan State Forest South \\
Tenuibranchiurus glypticus & Type Locality \\
& Bribie Island \\
& Beerburrum \\
\hline Tenuibranchiurus sp. nov. 2 & Beerburrum \\
\hline Tenuibranchiurus sp. nov. 3 & Hervey Bay \\
\hline & Tewantin \\
Tenuibranchiurus sp. nov. 4 & Lake Weyba \\
& Eumundi \\
\hline Tenuibranchiurus sp. nov. 5 & Gold Coast \\
\hline Gen. nov. sp. nov. 1 & Lennox Head \\
\hline Gen. nov. sp. nov. 1 & Broadwater National Park \\
\hline
\end{tabular}

463

464 ConCLUSIONS

465 Although genetic diversity within Tenuibranchiurus has previously been reported, no

466 quantification of this diversity had been undertaken. The multi-gene approach taken by this

467 study and use of several different analytical methods has identified not only several putative

468 species within the formerly monotypic Tenuibranchiurus, but a new genus with two putative

469 species. Although species identification of freshwater crayfish has traditionally been made

470 through morphological methods, the use of molecular methods in this study allowed the potential

471 pitfalls of plastic and/or cryptic morphological forms within crayfish to be avoided, and will

472 contribute in the development of a standardised method for dealing with species identification

473 within other freshwater crayfish.

474

475 ACKNOWLEDGEMENTS 
476 Many thanks are given to the volunteers that helped with the field work; Dr Seanan Wild,

477 Amanda Dawson, Dr Dianna Virkki, and Shane Howard. We are also grateful for additional 478 genetic material provided by Dr Andrew Bentley and Dr Quinton Burnham. 
480

481

482

483

484

485

486

487

488

489

490

491

492

493

494

495

496

497

498

499

500

501

502

503

504

505

506

507

508

509

510

511

512

513

514

515

516

517

518

519

520

521

522

523

524

525

\section{REFERENCES}

Apte S, Smith PJ, and Wallis GP. 2007. Mitochondrial phylogeography of New Zealand freshwater crayfishes, Paranephrops spp. Molecular Ecology 16:1897-1908. 10.1111/j.1365294X.2007.03224.x

Austin CM, and Knott B. 1996. Systematics of the Freshwater Crayfish Genus Cherax Erichson (Decapoda : Parastacidae) in South-western Australia: Electrophoretic, Morphological and Habitat Variation. Australian Journal of Zoology 44:223-258.

Avise JC. 2009. Phylogeography: retrospect and prospect. Journal of Biogeography 36:3-15. 10.1111/j.1365-2699.2008.02032.x

Bentley AI, Schmidt DJ, and Hughes JM. 2010. Extensive intraspecific genetic diversity of a freshwater crayfish in a biodiversity hotspot. Freshwater Biology 55:1861-1873.

Birky CW. 2013. Species Detection and Identification in Sexual Organisms Using Population Genetic Theory and DNA Sequences. PLoS ONE 8:e52544.

Birky CW, Adams J, Gemmel M, and Perry J. 2010. Using Population Genetic Theory and DNA Sequences for Species Detection and Identification in Asexual Organisms. PLoS ONE 5:e10609.

Birky CW, and Barraclough TG. 2009. Asexual Speciation. In: Schon I, Martens K, and van Dijk P, eds. Lost Sex. New York: Springer, Pages 201-216.

Birky CW, Wolf C, Maughan H, Herbertson L, and Henry E. 2005. Speciation and selection without sex. Hydrobiologia 546:29-45.

Blaxter ML. 2004. The promise of DNA taxonomy. Philosophical Transactions of the Royal Society B 359:669-679. 10.1098/rstb.2003.1447

Breinholt JW, Porter MG, and Crandall KA. 2012. Testing Phylogenetic Hypotheses of the Subgenera of the Freshwater Crayfish Genus Cambarus (Decapoda: Cambaridae). PLoS ONE 7:e46105.

Brower AVZ. 1999. Delimitation of Phylogenetic Species with DNA Sequences: A Critique of Davis and Nixon's Population Aggregation Analysis. Systematic Biology 48:199-213.

Buhay JE, Moni G, Mann N, and Crandall KA. 2007. Molecular taxonomy in the dark: Evolutionary history, phylogeography, and diversity of cave crayfish in the subgenus Aviticambarus, genus Cambarus. Molecular Phylogenetics and Evolution 42:435-448.

Colgan DJ, McLaughlan A, Wilson GDF, Livingston SP, Edgecombe GD, Macaranas JM, Cassis G, and Gray MR. 1998. Histone H3 and U2 snRNA DNA sequences and arthropod molecular evolution. Australian Journal of Zoology 46:419-437.

Cook BD, Pringle CM, and Hughes JM. 2008. Molecular evidence for sequential colonization and taxon cycling in freshwater decapod shrimps on a Caribbean island. Molecular Ecology 17:1066-1075.

Coughran J. 2005. New Crayfishes (Decapoda: Parastacidae: Euastacus) from Northeastern New South Wales, Australia. Records of the Australian Museum 57:361-374.

Coughran J, Dawkins KL, Hobson R, and Furse JM. 2012. Two new freshwater crayfishes (Decapoda: Parastacidae) from Whitsunday Island, The Coral Sea, Australia. Crustacean Research Special Number 7:45-57.

Dawkins KL, Furse JM, Wild CH, and Hughes JM. 2010. Distribution and population genetics of the freshwater crayfish genus Tenuibranchiurus (Decapoda: Parastacidae). Marine and Freshwater Research 61:1048-1055.

de Queiroz K. 1998. The general lineage concept of species, species criteria, and the process of speciation: A conceptual unification and terminological recommendations. In: Howard DJ, 
and Berlocher SH, eds. Endless forms: Species and speciation. New York: Oxford University Press, Pages 57-75.

de Queiroz K. 2007. Species Concepts and Species Delimitation. Systematic Biology 56:879-886. Doyle JJ, and Doyle JL. 1987. A rapid DNA isolation procedure for small quantities of leaf tissue. Phytochemistry Bulletin 19:11-15.

Druzhinina IS, Komoń-Zelazowska M, Ismaiel A, Jaklitsch W, Mullawa T, Samuels GJ, and Kubicek CP. 2012. Molecular phylogeny and species delimitation in the section Longibrachiatum of Trichoderma. Fungal Genetics and Biology 49:358-368.

Ebach MC, and Holdrege C. 2005. DNA barcoding is no substitute for taxonomy. Nature 434:697. Edgar RC. 2004. MUSCLE: multiple sequence alignment with high accuracy and high throughput. Nucleic Acids Research 32:1792-1797.

Edwards SV. 2008. Is a new and general theory of molecular systematics emerging? Evolution 63:1-19. 10.1111/j.1558-5646.2008.00549.x

Excoffier L, Laval G, and Schneider S. 2005. Arlequin ver. 3.0: An integrated software package for population genetics data analysis. Evolutionary Bioinformatics Online 1:47-50.

Furse JM, Dawkins KL, and Coughran J. 2013. Two new species of Euastacus (Decapoda: Parastacidae) from the Gondwana Rainforests of Central-Eastern Australia. Freshwater Crayfish 19:103-113.

GeneCodes. 2009. Sequencher (Version 4.9). Ann Arbor, Michigan: Gene Codes Corporation.

Hansen B, Adams M, Krasnicki T, and Richardson AMM. 2001. Substantial allozyme diversity in the freshwater crayfish Parastacoides tasmanicus supports extensive cryptic speciation. Invertebrate Taxonomy 15:667-679.

Hansen B, and Richardson AMM. 2006. A revision of the Tasmanian endemic freshwater crayfish genus Parastacoides (Crustacea: Decapoda: Parastacidae). Invertebrate Systematics 20:713-769.

Hebert PDN, Stoeckle MY, Zemlak TS, and Francis CM. 2004. Identification of Birds through DNA Barcodes. PLoS Biology 2:e312.

Hey J, and Machado CA. 2003. The study of structured populations - New hope for a difficult and divided science. Nature Reviews 4:535-543.

Horwitz P. 1988. Secondary sexual characteristics of females of the freshwater crayfish genus Engaeus (Decapoda, Parastacidae). Crustaceana 54:25-32.

Horwitz P. 1995. A preliminary key to the species of Decapoda (Crustacea: Malacostraca) found in Australian inland waters. Albury, Australia: Co-operative Research Centre for Freshwater Ecology.

Leasi F, Tang CQ, De Smet WH, and Fontaneto D. 2013. Cryptic diversity with wide salinity tolerance in the putative euryhaline Testudinella clypeata (Rotifera, Monogononta). Zoological Journal of the Linnean Society 168:17-28.

Lipscomb D, Platnick N, and Wheeler Q. 2003. The intellectual content of taxonomy: a comment on DNA taxonomy. TRENDS in Ecology \& Evolution 18:65-66.

Lou M, and Golding GB. 2010. Assigning sequences to species in the absence of large interspecific differences. Molecular Phylogenetics and Evolution 56:187-194.

Marrone F, Lo Brutto S, and Arculeo M. 2010. Molecular evidence for the presence of cryptic evolutionary lineages in the freshwater copepod genus Hemidiaptomus G.O. Sars, 1903 (Calanoida, Diaptomidae). Hydrobiologia 644:115-125. 
570

571

572

573

574

575

576

577

578

579

580

581

582

583

584

585

586

587

588

589

590

591

592

593

594

595

596

597

598

599

600

601

602

603

604

605

606

607

608

609

610

611

612

613

614

Mathews LM, Adams L, Anderson E, Basile M, Gottardi E, and Buckholt MA. 2008. Genetic and morphological evidence for substantial hidden biodiversity in a freshwater crayfish species complex. Molecular Phylogenetics and Evolution 48:126-135.

Meyer CP, and Paulay G. 2005. DNA Barcoding: Error Rates Based on Comprehensive Sampling. PLoS Biology 3:e422.

Miller MA, Pfeiffer W, and Schwartz T. 2010. Creating the CIPRES Science Gateway for inference of large phylogenetic trees: New Orleans, LA.

Monaghan MT, Balke M, Gregory TR, and Vogler AP. 2005. DNA-Based Species Delineation inTropical Beetles Using Mitochondrial and Nuclear Markers. Philosophical Transactions of the Royal Society B 360:1925-1933.

Murphy NP, and Austin CM. 2003. Molecular Taxonomy and Phylogenetics of Some Species of Australian Palaemonid Shrimps. Journal of Crustacean Biology 23:169-177.

Palumbi SR, Martin A, Romano S, McMillan WO, Stice L, and Grabowski G. 1991. A Simple Fool's Guide to PCR. Honolulu: University of Hawaii Press.

Posada D. 2008. jModelTest: Phylogenetic Model Averaging. Molecular Biology and Evolution 25:1253-1256.

Rach J, DeSalle R, Sarkar IN, Schierwater B, and Hadrys H. 2008. Character-based DNA barcoding allows discrimination of genera, species and populations in Odonata. Proceedings of the Royal Society London B 275:237-247.

Rambaut A. 2012. Figtree version 1.4.0. Available from http://ree.bio.ed.ac.uk/software/figtree/.

Reniers J, Vanschoenwinkel B, Rabet N, and Brendonck L. 2013. Mitochondrial gene trees support persistence of cold tolerant fairy shrimp throughout the Pleistocene glaciations in both southern and more northerly refugia. Hydrobiologia 714:155-167.

Riek EF. 1951. The freshwater crayfish (family Parastacidae) of Queensland, with an appendix describing other Australian species. Records of the Australian Museum 22:368-388.

Ronquist F, Teslenko M, van der Mark P, Ayres DL, Darling A, Höhna S, Larget B, Liu L, Suchard MA, and Huelsenbeck JP. 2012. MrBayes 3.2: efficient Bayesian phylogenetic inference and model choice across a large model space. Systematic Biology 61:539-542.

Schultz MB, Smith SA, Horwitz P, Richardson AMM, Crandall KA, and Austin CM. 2009. Evolution underground: A molecular phylogenetic investigation of Australian burrowing freshwater crayfish (Decapoda: Parastacidae) with particular focus on Engaeus Erichson. Molecular Phylogenetics and Evolution 50:580-598.

Schultz MB, Smith SA, Richardson AMM, Horwitz P, Crandall KA, and Austin CM. 2007. Cryptic diversity in Engaeus Erichson, Geocharax Clark and Gramastacus Riek (Decapoda:Parastacidae) revealed by mitochondrial 16S rDNA sequences. Invertebrate Systematics 21:569-587.

Seberg O, Humphries CJ, Knapp S, Stevenson DW, Petersen G, Scharff N, and Andersen NM. 2003. Shortcuts in systematics? A commentary on DNA-based taxonomy. TRENDS in Ecology \& Evolution 18:63-65.

Silva IC, Alves MJ, Paula J, and Hawkins SJ. 2010. Population differentiation of the shore crab Carcinus maenas (Brachyura: Portunidae) on the southwest English coast based on genetic and morphometric analyses. Scientia Marina 74:435-444.

Sinclair EA, Madsen A, Nelson J, and Crandall KA. 2011. Cryptic genetic divergence in the giant Tasmanian crayfish Atacopsis gouldi (Decapoda: Parastacidae): implications for conservation. Animal Conservation 14:87-97. 
615
Sites JW, and Marshall JC. 2003. Delimiting species: a Renaissance issue in systematic biology. TRENDS in Ecology \& Evolution 18:462-470.

Sneath PHA, and Sokal RR. 1973. Numerical taxonomy: The principles and practice of numerical classification. San Francisco: W.H. Freeman.

Sunnucks P. 2000. Efficient genetic markers for population biology. TRENDS in Ecology \& Evolution 15:199-203.

Tamura K, Peterson D, Peterson N, Stecher G, Nei M, and Kumar S. 2011. MEGA5: Molecular Evolutionary Genetics Analysis using Maximum Likelihood, Evolutionary Distance, and Maximum Parsimony Methods. Molecular Biology and Evolution 28:2731-2739.

Tautz D, Arctander P, Minelli A, Thomas RH, and Vogler AP. 2002. DNA points the way ahead in taxonomy. Nature 418:479.

Tautz D, Arctander P, Minelli A, Thomas RH, and Vogler AP. 2003. A plea for DNA taxonomy. TRENDS in Ecology \& Evolution 18:70-74.

van Velzen R, Weitschek E, Felici G, and Bakker FT. 2012. DNA Barcoding of Recently Diverged Species: Relative Performance of Matching Methods. PLOS ONE 7:e30490.

Wiens JJ, and Penkrot TA. 2002. Delimiting species using DNA and morphological variation and discordant species limits in spiny lizards (Sceloporus). Systematic Biology 51:69-91.

Wiens JJ, and Servedio MR. 2000. Species delimitation in systematics: inferring diagnostic differences between species. Proceedings of the Royal Society London B 267:631-636.

Will KP, Mischler BD, and Wheeler QD. 2005. The Perils of DNA Barcoding and the Need for Integrative Taxonomy. Systematic Biology 54:844-851.

Wright S. 1978. Evolution and the genetics of populations. Variability within and among natural populations. Vol. 4. Chicago, IL, USA: University of Chicago press.

Yang Z, and Rannala B. 2010. Bayesian species delimitation using multilocus sequence data. Proceedings of the National Academy of Sciences 107:9264-9269.

Yassin A, Markow TA, Narechania A, O'Grady PM, and deSalle R. 2010. The genus Drosophila as a model for testing tree- and character-based methods of species identification using DNA barcoding. Molecular Phylogenetics and Evolution 57:509-517. 